\title{
Leiomyosarcoma of the scrotum: a case report and literature review
}

\author{
Jiping Zeng ${ }^{1}$,, Grant Pollock$^{1}$, Joel Addams ${ }^{2}$, Erika Bracamonte ${ }^{2}$, Juan Chipollini ${ }^{1}$ \\ ${ }^{1}$ Department of Urology, University of Arizona College of Medicine, Tucson, AZ, USA; ${ }^{2}$ Department of Pathology, University of Arizona College \\ of Medicine, Tucson, AZ, USA \\ Correspondence to: Juan Chipollini, MD. Department of Urology, University of Arizona College of Medicine, 1501 N. Campbell Avenue, PO Box \\ 245077, Tucson, AZ 85724-5077, USA. Email: jchipollini@surgery.arizona.edu.
}

\begin{abstract}
Leiomyosarcoma (LMS) is one of the most common forms of soft tissue sarcoma with approximately 2,500 cases per year in the United States. The symptoms LMS vary depending upon the location, size, and spread of the tumor. In early stages, it may not be associated with any obvious symptoms so diagnosis and treatment may be delayed. In some cases, it can grow quickly and behave aggressively. Most types of LMS occur in the abdomen or in the uterus; although, scrotal LMS can be a very rare presentation of the disease. Here we present our case of a large, ulcerated scrotal LMS originating from subcutaneous tissue but not invading spermatic cord or tunica. Radical orchiectomy with high ligation of spermatic cord was performed, and patient had an uneventful postoperative course. This disease entity remains rare in the literature, and warrants larger studies in order to better understand treatment and oncologic outcomes. When LMS is identified early and is removed by surgical excision, prognosis can be good and full recovery quite likely. When LMS is already large or has spread to other parts of the body, treatment is relatively more complex and the prognosis poor. Hence, prompt diagnosis and treatment of genitourinary LMS require prompt attention, referral to tertiary, referral center should be strongly considered.
\end{abstract}

Keywords: Scrotal leiomyosarcoma; hemiscrotectomy; case report

Submitted Aug 18, 2020. Accepted for publication Dec 07, 2020.

doi: $10.21037 /$ tau-20-1184

View this article at: http://dx.doi.org/10.21037/tau-20-1184

\section{Introduction}

Leiomyosarcoma (LMS) is one of the most common forms of soft tissue sarcoma, with approximately 2,500 cases per year in the United States according to National Cancer Institute (1). LMS of the scrotum is very rare. The first case report of scrotal LMS was described in 1964 by Karlinsky et al. (2). Since then, there have been 51 cases reported in the literature. It can originate from testicular tunica (48\%), spermatic cord (48\%), epididymis (2\%) and dartos muscle, as well as subcutaneous tissue of the scrotum (2\%). Here we present our case of a large ulcerated scrotal LMS originating from subcutaneous tissue that does not invade spermatic cord or tunica. Clinical presentation, surgical technique and pathological examination were described. We present the following article in accordance with the CARE reporting checklist (available at: http://dx.doi.org/10.21037/ tau-20-1184).

\section{Case presentation}

A 46-year-old male with PMHx of alcohol abuse and schizoaffective disorder presented to emergency room with scrotal bleeding. He had a slow growing scrotal mass for the past 10 years and it started to bleed from one day ago. He never sought medical attention prior. Physical

^ ORCID: 0000-0002-1097-3020. 

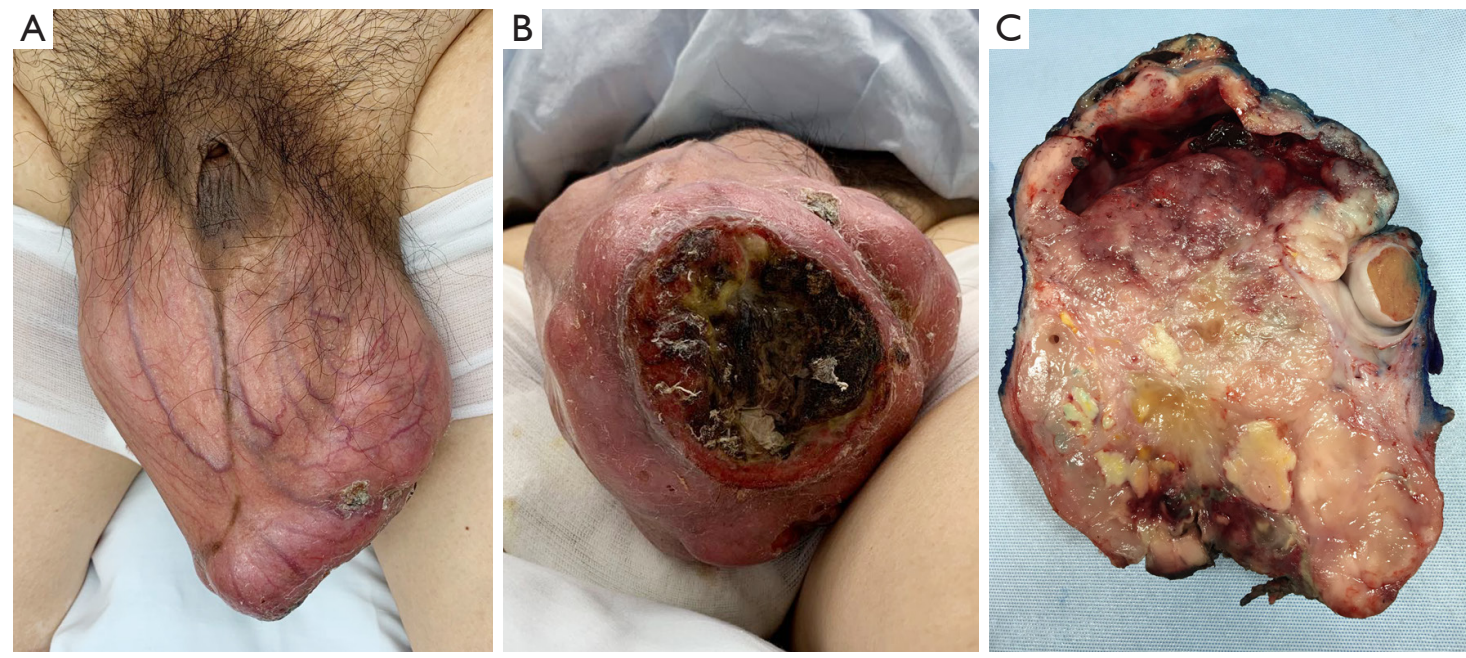

Figure 1 (A) Large scrotal mass with ulcerated surface at the base. This was causing recurrent bleeding episodes that prompted the emergency room visits. (B) Buried penis due to mass effect. Prominent subcutaneous vessels can be visualized. (C) The gross specimen shows tan-pink firm lesion with a large hemorrhagic cystic space and areas of yellow necrosis. The testicle is unaffected.

exam showed $18 \times 12 \times 12 \mathrm{~cm}$ scrotal mass with ulcerated skin at the scrotal base; buried penis due to mass effect (Figure 1A,B). All procedures performed in studies involving human participants were in accordance with the ethical standards of the institutional and/or national research committee(s) and with the Helsinki Declaration (as revised in 2013). Written informed consent was obtained from the patient for publication of this study and any accompanying images.

Hgb was $9.9 \mathrm{~g} / \mathrm{dL}$. AFP, $\beta$-HCG and LDH were within normal range. He underwent scrotal ultrasound which demonstrated large scrotal mass with heterogeneous echogenicity and increased vascularity. There was a large central cystic component. Bilateral testicles were unremarkable. CT abdomen pelvis with contrast demonstrated bilateral mildly enlarged inguinal lymph nodes favoring reactive. His bleeding was controlled after local wound care. He was instructed to follow-up in clinic to discuss surgical treatment however he was lost to follow-up.

Two weeks later patient presented to ED with another bleeding episode with $\mathrm{Hgb}$ of $7.4 \mathrm{~g} / \mathrm{dL}$. He was admitted for hospital for local wound care and transfusion. $\mathrm{He}$ was taken to OR for left hemiscrotectomy, high ligation of spermatic cord and right orchiopexy. Patient had an uneventful postoperative course and was discharged on POD\#1. At three-month follow-up, patient recovered well and reported resolution in his symptoms. However, he declined further surveillance.

\section{Surgical technique}

We started by making an incision slightly above the edge of the mass in a transverse fashion. There was increased vascularity around the mass from subcutaneous vessels feeding the mass, which were carefully controlled. We circumferentially dissected this mass, which appeared quite necrotic with some evidence of purulence at the center which were sent for culture.

The gubernaculum was taken with 0 silk ties. The medial border was also dissected carefully and the right testicle was able to be gently spared and tucked away from our area of dissection superiorly. We were able to circumferentially dissect the left spermatic cord. However, the left testicle appeared to be buried inside the mass. Decision was made to proceed with orchiectomy and high ligation of spermatic cord to ensure negative surgical margin. Right orchiopexy was performed. After placement of Penrose drain in left hemiscrotum, we close the large defect by layers with the spared healthy-appearing skin.

\section{Pathological examination}

Gross examination: the specimen weighed 1,337 grams and measured $17.4 \times 12.2 \times 12.1 \mathrm{~cm}^{3}$. The testicular mass was lobulated and well-encapsulated, with an ulcerated 

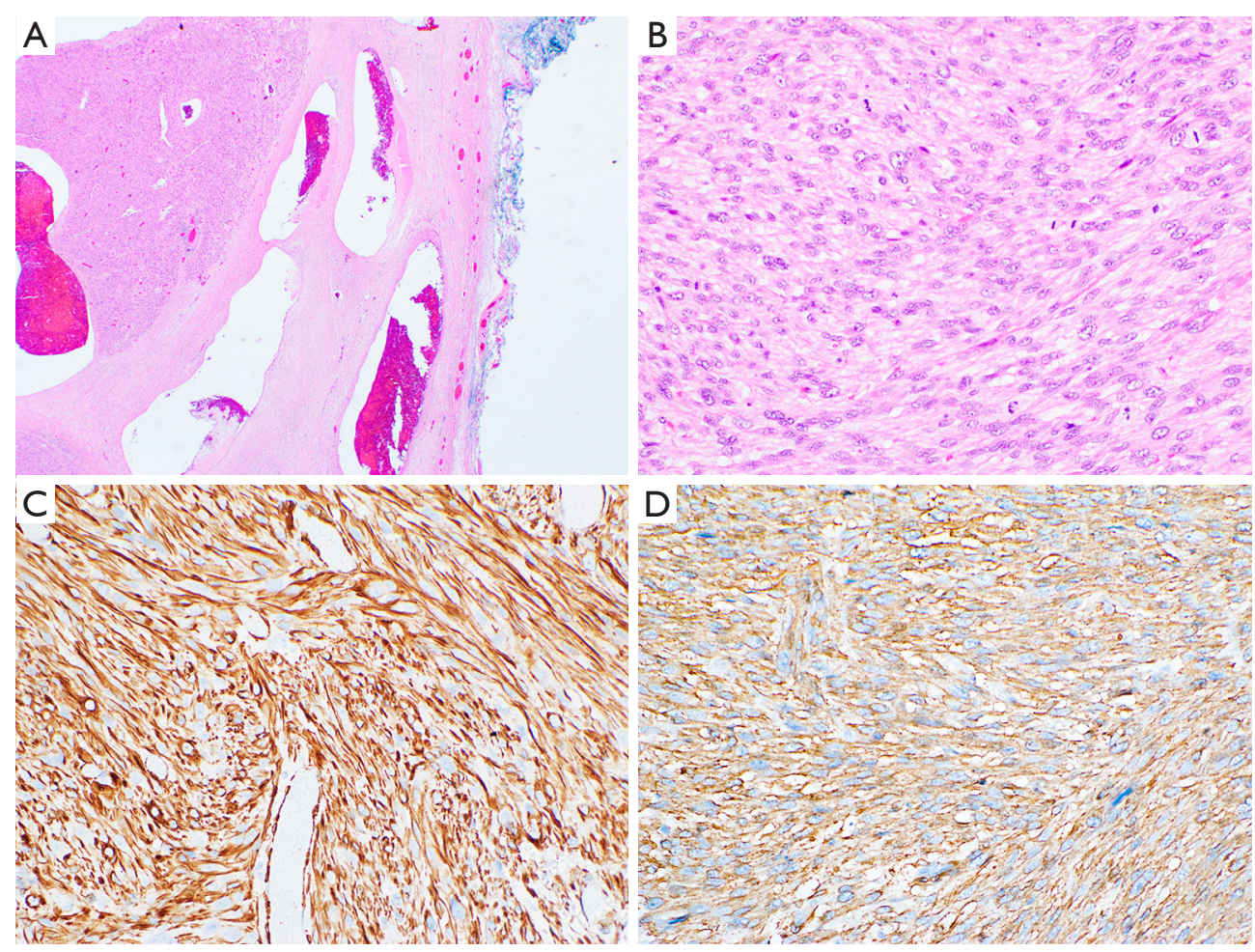

Figure 2 (A) Tumor is present as a well-circumscribed solid mass lesion with large compressed peripheral vessels and fibrous capsule (H\&E, 20× mag). (B) Tumor cells grow in interlacing fascicles, often with spindled morphology and moderate amounts of pale eosinophilic cytoplasm. Moderate nuclear atypia is present, and frequent mitotic figures are identified (H\&E, 100× mag). (C,D) Tumor cells are diffusely and strongly positive for Caldesmon (A) and smooth muscle actin (B) by immunohistochemistry (each 200× mag).

area measuring $5.9 \times 6.4 \mathrm{~cm}^{2}$. On sectioning the mass was $90 \%$ solid, composed of tan-pink parenchyma with areas of yellow necrosis, and contained an apical hemorrhagic cystic space $\left(8.4 \times 4.4 \times 4.2 \mathrm{~cm}^{3}\right)$. The spermatic cord and testicle were identified on the periphery of the specimen, appeared uninvolved by tumor, and were otherwise unremarkable (Figure 1C).

Microscopic examination: the tumor consisted of spindle shaped cells with fascicular architecture and areas of hyalinization. Approximately $20 \%$ coagulative necrosis was present. Cells contained moderate amounts of eosinophilic cytoplasm and showed moderate to marked nuclear pleomorphism, with focally prominent red nucleoli. Mitotic activity was brisk, with up to 19 mitoses/10 HPF, and scattered atypical mitotic figures (Figure $2 A, B$ ).

Immunohistochemistry: the tumor cells were diffusely positive for Caldesmon and smooth muscle actin, and negative for desmin, S100, SOX10, and CD34 (Figure 2C,D). This immunophenotype is indicative of smooth muscle origin. The tumor was graded according to the Sarcoma FNCLCC grading system as grade 2 of 3 , based on differentiation score 2 for conventional LMS, mitotic count score 2 (19 per $10 \mathrm{HPF}$ ), and necrosis score 1 ( $20 \%$ of specimen), for a total score of $5 / 8$.

All procedures performed in studies involving human participants were in accordance with the ethical standards of the institutional and/or national research committee(s) and with the Helsinki Declaration (as revised in 2013). Written informed consent was obtained from the patient.

\section{Discussion}

The behavior of LMS is site related, and data on paratesticular LMS are limited. The age of presentation varies widely, ranging from 34-86 years (median 64 years) (3). It usually presents with rubbery, firm, nontender and irregular mass. As it grows slowly, patients tend to ignore the mass and seek medical attention until it is bothersome. In those who have suffered from psychiatric disorders and substance abuse, a delayed in seeking medical attention is 
often seen. The size can range from $2-17 \mathrm{~cm}$, depending on time of presentation. The largest LMS reported in 37 lbs, measuring $50 \times 35 \times 25 \mathrm{~cm}^{3}$ (4). Occasionally patient may present with complication from the mass, such as superimposed infection or bleeding from ulceration.

The work-up typically includes serum testicular cancer markers (AFP, $\beta$-HCG and LDH), scrotal ultrasound and CT abdomen/pelvis with contrast. Tumor markers are typically negative. There has been one case report of scrotal LMS with increased $\beta$-HCG which normalized 6 weeks after complete resection (5). Ultrasound sonography typically shows well defined masses with a soft tissue consistency that may show hemorrhage, necrosis, or cystic degeneration. Solid components of the tumor may demonstrate hypervascularity on color Doppler imaging (6). If local invasion is suspected, MRI may have better soft tissue resolution to delineate the surrounding structures (7).

Pathological examination usually reveals classic features of soft tissue LMS, displaying perpendicularly oriented fascicles of cells with brightly eosinophilic cytoplasm containing delicate longitudinal fibrils and blunt-ended nuclei. Tumors are consistent with immunohistochemical profiles characteristic of smooth muscle differentiation, including expression of smooth muscle actin, and musclespecific actin. CD34 positivity is unusual but it has been reported before. Similarly, desmin is expected to be negative but it can be seen in some tumors. For example, concurrent positive staining of CD34 and desmin was reported in 3/9 cases (33.3\%) by Fisher et al. (3). An important distinction is symplastic leiomyoma which can have bizarre nuclei. However, these benign tumors are devoid of mitotic figures and has low Ki-67 positivity. On the contrary, LMS had high nuclear/cytoplasmic ratio, high cellularity, nuclear pleomorphism, and hyperchromasia (8).

Given its rarity, there is no guideline available for the best management option. Surgical treatment appears to be the choice in previous reports. Radical orchiectomy with high ligation of spermatic cord is recommended. The local recurrence-free interval at 5 years is higher with a margin $>10 \mathrm{~mm}(84 \%)$ than that of $0 \mathrm{~mm}(58 \%)$ or $1-9 \mathrm{~mm}$ (58\%) (9). Therefore, aggressive surgical approach to achieve negative margin is reasonable. Depending on the tumor size, local flaps or free-pedicle flaps may be required for reconstruction. Adjuvant therapy, such as chemotherapy and radiation have limited data. It is usually applied when the surgical margin is positive or the suspicion for local recurrence is high $(10,11)$. However, given the fact that it belongs to sarcoma, some authors have advocated that all patients with scrotal LMS should receive radiation therapy in addition to surgery to decrease chance of local recurrence (12-14). This is based on the success of adjuvant radiotherapy in the management of sarcomas in general (15).

Local recurrence or metastasis to lymph nodes have been reported. Repeat resection is feasible $(16,17)$. In patients who underwent reoperative wide resection after a prior incomplete resection, a trend toward improved diseasefree survival was noted (16). Komeya et al. reported a case with $7.5 \mathrm{~cm}$ retroperitoneal mass 34 months after the surgery (18). Retroperitoneal mass excision confirmed metastatic LMS. The role of prophylactic lymph node dissection remains unclear.

In conclusion, paratesticular LMS is a rare disease entity that can be treated with wide resection and high ligation of spermatic cord. Efforts should be made to achieve negative margin. The role of adjuvant therapy in the setting of clean margin remains controversial. Close follow-up after surgery is important to monitor for local and distant recurrence.

\section{Acknowledgments}

Funding: None.

\section{Footnote}

Reporting Checklist: The authors have completed the CARE reporting checklist. Available at http://dx.doi.org/10.21037/ tau-20-1184

Conflicts of Interest: All authors have completed the ICMJE uniform disclosure form (available at http://dx.doi. org/10.21037/tau-20-1184). The authors have no other conflicts of interest to declare.

Ethical Statement: The authors are accountable for all aspects of the work in ensuring that questions related to the accuracy or integrity of any part of the work are appropriately investigated and resolved. All procedures performed in studies involving human participants were in accordance with the ethical standards of the institutional and/or national research committee(s) and with the Helsinki Declaration (as revised in 2013). Written informed consent was obtained from the patient for publication of this study and any accompanying images.

Open Access Statement: This is an Open Access article distributed in accordance with the Creative Commons 
Attribution-NonCommercial-NoDerivs 4.0 International License (CC BY-NC-ND 4.0), which permits the noncommercial replication and distribution of the article with the strict proviso that no changes or edits are made and the original work is properly cited (including links to both the formal publication through the relevant DOI and the license). See: https://creativecommons.org/licenses/by-nc-nd/4.0/.

\section{References}

1. National Cancer Institute. Cancer Stat Facts: Soft Tissue. Available online: https://seercancergov/statfacts/html/ softhtml

2. Karlinsky W, Taylor JR. Leiomyosarcoma of the scrotal contents. case report. Winnipeg Clin Q 1964;17:32-4.

3. Fisher C, Goldblum JR, Epstein JI, et al. Leiomyosarcoma of the paratesticular region: a clinicopathologic study. Am J Surg Pathol 2001;25:1143-9.

4. Echenique JE, Tully S, Tickman R, et al. A 37-pound scrotal leiomyosarcoma: a case report and literature review. J Urol 1987;138:1245-6.

5. Brandt MP, Hoefner T, Gust KM, et al. Rare Case of Excessive Beta-Human Chorionic Gonadotropin Producing Intrascrotal Leiomyosarcoma: Diagnostic Pitfalls and Therapeutic Implications. Clin Genitourin Cancer 2016;14:e409-12.

6. Secil M, Kefi A, Gulbahar F, et al. Sonographic features of spermatic cord leiomyosarcoma. J Ultrasound Med 2004;23:973-6; quiz 977-8.

7. Woodward PJ, Schwab CM, Sesterhenn IA. From the archives of the AFIP: extratesticular scrotal masses: radiologic-pathologic correlation. Radiographics

Cite this article as: Zeng J, Pollock G, Addams J, Bracamonte E, Chipollini J. Leiomyosarcoma of the scrotum: a case report and literature review. Transl Androl Urol 2021;10(3):1342-1346. doi: $10.21037 /$ tau-20-1184
2003;23:215-40.

8. Matoso A, Chen S, Plaza JA, et al. Symplastic leiomyomas of the scrotum: a comparative study to usual leiomyomas and leiomyosarcomas. Am J Surg Pathol 2014;38:1410-7.

9. Dalton DP, Rushovich AM, Victor TA, et al. Leiomyosarcoma of the scrotum in a man who had received scrotal irradiation as a child. J Urol 1988;139:136-8.

10. Rajkomar K, Mundy I. Leiomyosarcoma of the scrotum--a rare tumour. N Z Med J 2007;120:U2835.

11. Ballo MT, Zagars GK, Pisters PW, et al. Spermatic cord sarcoma: outcome, patterns of failure and management. J Urol 2001;166:1306-10.

12. Moloney J, Drumm J, Fanning DM. A rare case of paratesticular leiomyosarcoma. Clin Pract 2012;2:e29.

13. Russo P, Brady MS, Conlon K, et al. Adult urological sarcoma. J Urol 1992;147:1032-6; discussion 6-7.

14. Kawanishi H, Yoshida T, Kouhei N, et al. Leiomyosarcoma of the spermatic cord: a case report. Hinyokika Kiyo 2003;49:551-4.

15. Bauer HC, Alvegard TA, Berlin O, et al. The Scandinavian Sarcoma Group Register 1986-2001. Acta Orthop Scand Suppl 2004;75:8-10.

16. Coleman J, Brennan MF, Alektiar K, et al. Adult spermatic cord sarcomas: management and results. Ann Surg Oncol 2003;10:669-75.

17. Agrawal R, Gupta M, Mohan N, et al. Recurrent leiomyosarcoma scrotum: An important differential in scrotal masses. Indian J Pathol Microbiol 2017;60:581-3.

18. Komeya M, Sahoda T, Sugiura S, et al. Metastasis of primary testicular leiomyosarcoma to the retroperitoneal space. Indian J Urol 2012;28:343-6. 